\title{
Differential Expression of MicroRNAs in CD34+ Cells of 5q- Syndrome
}

\author{
Hana Votavova ${ }^{1 *}$, Martina Grmanova', Michaela Dostalova Merkerova', Monika Belickova', Alzbeta Vasikova', \\ Radana Neuwirtova², Jaroslav Cermak ${ }^{1,3}$
}

\begin{abstract}
Background: Myelodysplastic syndrome with isolated chromosome $5 q$ deletion ( $5 q$ - syndrome) is a clonal stem cell disorder characterized by ineffective hematopoiesis. MicroRNAs (miRNAs) are important regulators of hematopoiesis and their aberrant expression was detected in some clonal hematopoietic disorders. We thus analyzed miRNA expressions in bone marrow CD34+ cells of 5q- syndrome patients. Further, we studied gene expressions of miR-143, miR-145, miR-378 and miR-146a mapped within the $5 q$ deletion.

Results: Using microarrays we identified 21 differently expressed miRNAs in 5q- patients compared to controls. Especially, miR-34a was markedly overexpressed in 5q- patients, suggesting its role in an increased apoptosis of bone marrow progenitors. Out of four miRNAs at del(5q), only miR-378 and miR-146a showed reduced gene expression in the patients. An integrative analysis of mRNA profiles and predicted putative targets defined potential downstream targets of the deregulated miRNAs. The list of targets included several genes that play an important role in the regulation of hematopoiesis (e.g. KLF4, LEF1, SPI1).

Conclusions: The study demonstrates global overexpression of miRNAs is associated with $5 q$ - phenotype. Identification of hematopoiesis-relevant target genes indicates that the deregulated miRNAs may be involved in the pathogenesis of $5 \mathrm{q}$ - syndrome by a modulation of these targets. The expression data on miRNAs at del(5q) suggest the presence of mechanisms for compensation of a gene dosage.
\end{abstract}

\section{Background}

The 5q- syndrome is a distinct subtype of myelodysplastic syndrome (MDS) with typical molecular, cytogenetic, morphological, clinical and prognostic features; an isolated interstitial deletion of the long arm of chromosome 5 [del(5q)], bone marrow blasts less than $5 \%$, normal or often increased platelet count, macrocytic anemia, typical megakaryocytes and often hypoplastic erythropoiesis. Pathophysiological basis of 5q- syndrome is likely associated with haploinsufficiency of genes mapping to the deleted region at 5q31-q32, so called commonly deleted region (CDR). However, other mechanisms may contribute to the ineffective hematopoiesis in 5q- syndrome.

MicroRNAs (miRNAs) are small non-coding RNAs that negatively modulate expression of complementary genes by translation inhibition or mRNA degradation. MiRNAs

\footnotetext{
* Correspondence: Hana.Bruchova@uhkt.cz

'Department of Molecular Genetics, Institute of Hematology and Blood Transfusion, Prague, Czech Republic

Full list of author information is available at the end of the article
}

have been shown to be important regulators of hematopoiesis and their aberrant expression was found in some clonal hematopoietic disorders such as polycythemia vera $[1,2]$. In MDS, Pons et al. analyzed gene expression of 25 hematopoiesis-relevant miRNAs in mononuclear cells and examined possible association of their expression with other parameters such as disease stage, risk score etc. [3]. Hussein et al. performed miRNA expression profiling in total bone marrow (BM) cells of MDS patients with normal karyotype and distinct cytogenetic aberrations [4]. However, there is limited information on miRNA regulation in BM progenitors of MDS. Thus, we determined miRNA expression patterns in BM CD34+ cells of 5q- syndrome patients and searched for differentially expressed miRNAs that might contribute to the pathogenesis of 5q- syndrome. To define potential downstream targets of the deregulated miRNAs in 5q- patients, we combined mRNA microarray data of the tested patients with those of in silico miRNA target predictions. Further, we attempted to address a gene dosage effect of

\section{Biomed Central}


$\operatorname{del}(5 q)$ on gene expression of the miRNAs mapped within the deletion in BM progenitors and peripheral blood cells of $5 q$ - patients.

\section{Results and Discussion}

Ineffective hematopoiesis, the hallmark of MDS, arises from defective hematopoietic progenitors that display retarded maturation capacity, premature apoptotic death, and impaired growth and responsiveness to growth factors. However, recent studies of miRNAs in MDS were performed on partly separated or nonseparated cells of bone marrow [3,4]. In this study, we thus focused on progenitor cells of $5 \mathrm{q}$ - syndrome in order to determine miRNA expressions specific for this cell population.

MiRNA expression profiles were assayed in bone marrow (BM) CD34+ cells from 5q- syndrome patients and controls using TaqMan arrays with 365 probes. Out of the miRNA set, transcripts of 183 miRNAs at average were expressed at the detectable level $\left(\mathrm{C}_{\mathrm{T}}<35\right)$. Comparative analysis determined differential expression of 21 miRNAs between 5q- patients and controls at $\mathrm{p}<0.05$ after Bonferroni correction; increased expression of 17 miRNAs and decreased expression of 4 miRNAs in $5 \mathrm{q}-$ patients. Unsupervised hierarchical clustering performed using this miRNA set clearly discriminated $5 \mathrm{q}$ - patients from controls [Figure 1]. Higher proportion of upregulated miRNAs inversely correlated with global down-regulation of mRNA expressions in MDS reported

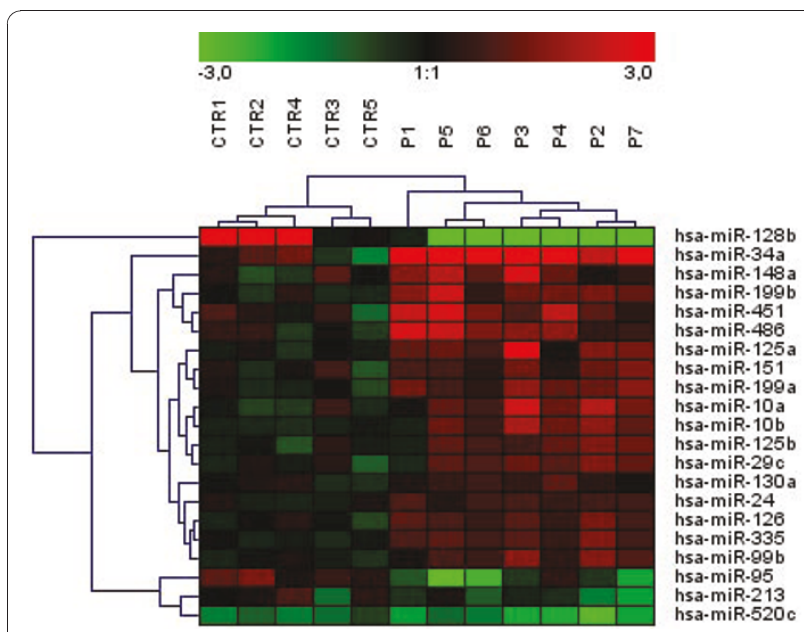

Figure 1 Unsupervised hierarchical clustering of 21 differentially expressed miRNAs between controls and 5qpatients ( $p<0.05$ after Bonferroni correction). The relative miRNA expression changes are expressed by a color gradient intensity scale, as shown at the top. The lightest green color indicates maximal decrease and the lightest red color indicates maximal increase of gene expression. Each column represents a separate CD34+ sample and each row a single miRNA. CTR- control, P- patient. previously [5]. The averaged fold changes of miRNA expressions in $5 \mathrm{q}$ - patients were summarized in the Additional file 1.

Pons et al. analyzed expression of 25 hematopoietic miRNAs in BM mononuclear cells of MDS patients and identified 12 overexpressed miRNAs including miR-10a, $m i R-10 b$ and $m i R-126$ [3]. In our study, we also detected up-regulation of these miRNAs in $5 \mathrm{q}$ - progenitors. miR$10 a$ and $m i R-10 b$ genes are embedded in the cluster of $H O X$ genes that are implicated in early hematopoiesis as well as leukemogenesis. Expression of these miRNAs correlates with $H O X$ gene expression, suggesting their modulation by the same regulators as those of $H O X$ genes. For example, $m i R-126$ is co-expressed with HOXA9 mRNA in hematopoietic stem cells and downregulated in parallel during progenitor differentiation [6]. Overexpression of HOXA9 was observed in BM samples of unselected MDS patients [7] and it caused stem cell expansion in BM mouse cells [8]. It suggests that up-regulation of $m i R-126$ may be associated with the clonal cell expansion in $5 \mathrm{q}$ - syndrome. $m i R-99 b$ and $m i R-130 a$, up-regulated in our $5 q$ - patients, represented other miRNAs involved in the regulation of $H O X$ genes.

miR-34a showed the most up-regulated expression in $5 \mathrm{q}$ - patients compared to controls (12-fold at average, $\mathrm{p}<0.01)$. This miRNA is a direct proapoptotic transcriptional target of $p 53$ that in turn regulates the expression of some $p 53$ target genes. Induced expression of $m i R-34 a$ activates apoptosis by inhibition of BCL2 target gene [9]. Thus, high expression of $m i R-34 a$ in $5 \mathrm{q}-$ patients is likely to be related to an increased apoptosis of $\mathrm{BM}$ progenitors. On the other hand, decreased expression of $m i R-34 a$ (e.g. due to $p 53$ mutations) may be a selective advantage in malignant cells.

In $5 \mathrm{q}$ - patients, we detected increased expressions of miR-451 and $m i R-223$ ( $\mathrm{p}<0.01$ and $\mathrm{p}=0.0503$ after Bonferroni correction) involved in the regulation of erythropoiesis that is defective in $5 \mathrm{q}$ - syndrome. $m i R-451$ is a positive regulator of erythroid cell maturation. Its expression is very low at early stages of erythroid differentiation and rapidly increases with maturation progress [10]. However, the tested progenitors of 5q- patients displayed significant overexpression of $m i R-451$. Target gene(s) of human $m i R-451$ are still unclear. In zebrafish, $m i R-451$ transcription is activated by a hematopoietic transcription factor GATA-1 and it likely controls erythropoiesis via GATA-2 target gene [11].

$m i R-223$ is a transcriptional target of CEBPA and plays an essential role in granulopoiesis in which targets $E 2 F 1$ [12]. In erythropoiesis, ectopic expression of $m i R$ 223 suppresses protein levels of LMO2 and thus impairs cell differentiation. Further, hematopoietic progenitor cells transduced with $m i R-223$ show a significant reduction of their erythroid clonogenic capacity [13]. 
It suggests that down-modulation of this miRNA is required for erythroid progenitor recruitment and commitment. We may speculate that the overexpression of $m i R-451$ and $m i R-223$ interferes with the erythroid differentiation in $5 \mathrm{q}$ - syndrome.

In total BM cells, Hussein et al. detected increased transcript levels of $m i R-199 a, m i R-125 a$, and $m i R-125 b$ in MDS patients with associated $\operatorname{del}(5 \mathrm{q})$ [4]. We observed the same expression pattern of these miRNAs in $5 \mathrm{q}-\mathrm{BM}$ progenitors. $m i R-125 a$ and $m i R-125 b$ are members of a multigene family located in paralogous clusters. The miR-125a cluster on chromosome 19 includes $m i R-99 b$ and let-7e, whereas the $m i R-125 b$ cluster on chromosome 21 consists of miR-99a and let-7c. We might conclude that these clusters were upregulated in $5 \mathrm{q}$ - progenitors since $m i R-125 a, m i R-125 b$, $m i R-99 b, m i R-99 a$ and let-7e showed increased levels before post p-value correction. Strong up-regulation of $m i R-125 b$ is also found in MDS and AML with $\mathrm{t}(2 ; 11)$ (p21;q23) and in vitro studies show its interference with primary human CD34+ cell differentiation [14]. In leukemic cell lines, $m i R-125 b$ inhibits monocytic and granulocytic differentiation [14]. $m i R-125 a$ is preferentially expressed in long-term hematopoietic stem cells and its activity is associated with induction of stem cell expansion [15].

Expression of $m i R-128 b$ showed significant decrease in our $5 \mathrm{q}$ - patients. In contrast, it is overexpressed in acute leukemias and represents one of the most discriminatory miRNAs for ALL and AML [16]. Interestingly, miR-128b is down-regulated in $M L L$-rearranged ALL and targets $M L L$ and $A F 4$ genes involved in the fusion (including their fused variants) [17]. Both these target genes play an important role in leukemogenesis. Further, we detected down-regulation of $m i R-342$ expression in 5qpatients. This miRNA likely plays a positive regulatory role in the granulocytic differentiation as demonstrated in acute promyelocytic leukemia treated by all-transretinoic acid [18].

We attempted to address a gene dosage effect of del (5q) on expression of the miRNAs mapped within this deletion. Using a singleplex qRT-PCR, we analyzed gene expression of $m i R-143$, $m i R-145, m i R-378$ and $m i R-146 a$ in peripheral blood (PB) granulocytes, monocytes, and Tlymphocytes of $5 \mathrm{q}$ - patients and controls and in BM CD34+ cells used for miRNA expression profiling [Figure 2]. The miRNAs showed similar gene expression patterns in various $\mathrm{PB}$ cells. However, the pattern in BM progenitors was considerably different, demonstrating tissue-specific regulation of these miRNAs. In PB cells, miR-143 and $m i R-145$ were expressed at the lower levels in patient granulocytes $(m i R-143$ at $\mathrm{p}<0.01)$ and T-lymphocytes. In patient monocytes, both miRNAs were expressed at the control level. $m i R-378$ showed non-significant up-regulation in patient granulocytes and T-lymphocytes. miR-146a was up-regulated in all PB patient cells and reached statistical significance in granulocytes $(\mathrm{p}<0.01)$. In BM CD34+ patient cells, $m i R-143$ and $m i R-145$ expressions showed slight up-regulation and transcript levels of $m i R-378$ and $m i R-146 a(\mathrm{p}=0.05)$ were reduced. Similar transcript levels of these miRNAs in BM CD34+ cells of 5q- patients were found by others [19]. Moreover, Boultwood et al. determined similar expression pattern of these miRNAs in BM CD34+ cells of refractory anemia patients with normal karyotype, demonstrating their 5qsyndrome non-specific regulation. In contradiction with these findings, Straczynowski et al. detected significant down-regulation of $m i R-143$ and $m i R-145$ in 5 q- marrow cells and down-regulation of $m i R-145$ and $m i R-146 a$ in CD34+ cells of three $5 q$ - patients [20]. In mouse, they further showed that knock-down of miR-145 and miR$146 a$ caused thrombocytosis, neutropenia and megakaryocytic dysplasia [20]. The result discrepancy might arise from different numbers of tested patients and/or different clinical parameters of patients in the cohort (e.g. number of patients with thrombocytosis). Collectively, our results demonstrate that gene expression of the miRNAs in the deleted region is not significantly affected (resp. reduced) by the loss of one allele. We assume that there are mechanisms for compensation of the gene dosage (e.g. epigenetic modification causing higher expression of the retained allele) and the miRNAs cooperate to induce $5 q$ - phenotype.

Target genes of some miRNAs at $\operatorname{del}(5 \mathrm{q})$ were determined by functional studies. TRAF6 is target gene of miR-146. $m i R-145$ targets TIRAP that is upstream of TRAF6 in Toll-like receptor pathway [20]. Induced expression of TRAF6 or knock-down of $m i R-145$ and $m i R-146 a$ in mouse BM cells leads to the $5 q$ - like phenotype [20]. In our study, $m i R-146 a$ expression was down-regulated by $30 \%$ in BM CD34+ cells of $5 q-$ patients. Interestingly, gene expression of this miRNA showed increased levels in PB patient cells. Pons et al. detected also overexpression of $m i R-146$ in BM mononuclear cells of MDS patients with $\operatorname{del}(5 \mathrm{q})$ [3].

To define potential downstream targets of the deregulated miRNAs in 5q- patients, we performed an integrative analysis of differently expressed mRNAs and in silico predicted targets of the miRNAs. Messenger RNA profiles of CD34+ cells of the tested subjects have been previously assayed using Illumina HumanRef-8 v2 Expression BeadChips with 22,000 gene probes. Comparative analysis of $5 \mathrm{q}$ - patients and controls detected 246 differently expressed mRNAs $(\mathrm{p}<0.01)$ [5]. We observed an inverse association between expressions of these miRNAs and targets; e.g. miR-199a and CCDC34, MRPL22; miR-34a and LEF1, KLF4, SPI1, NR4A2. All results are summarized in the Table 1. 


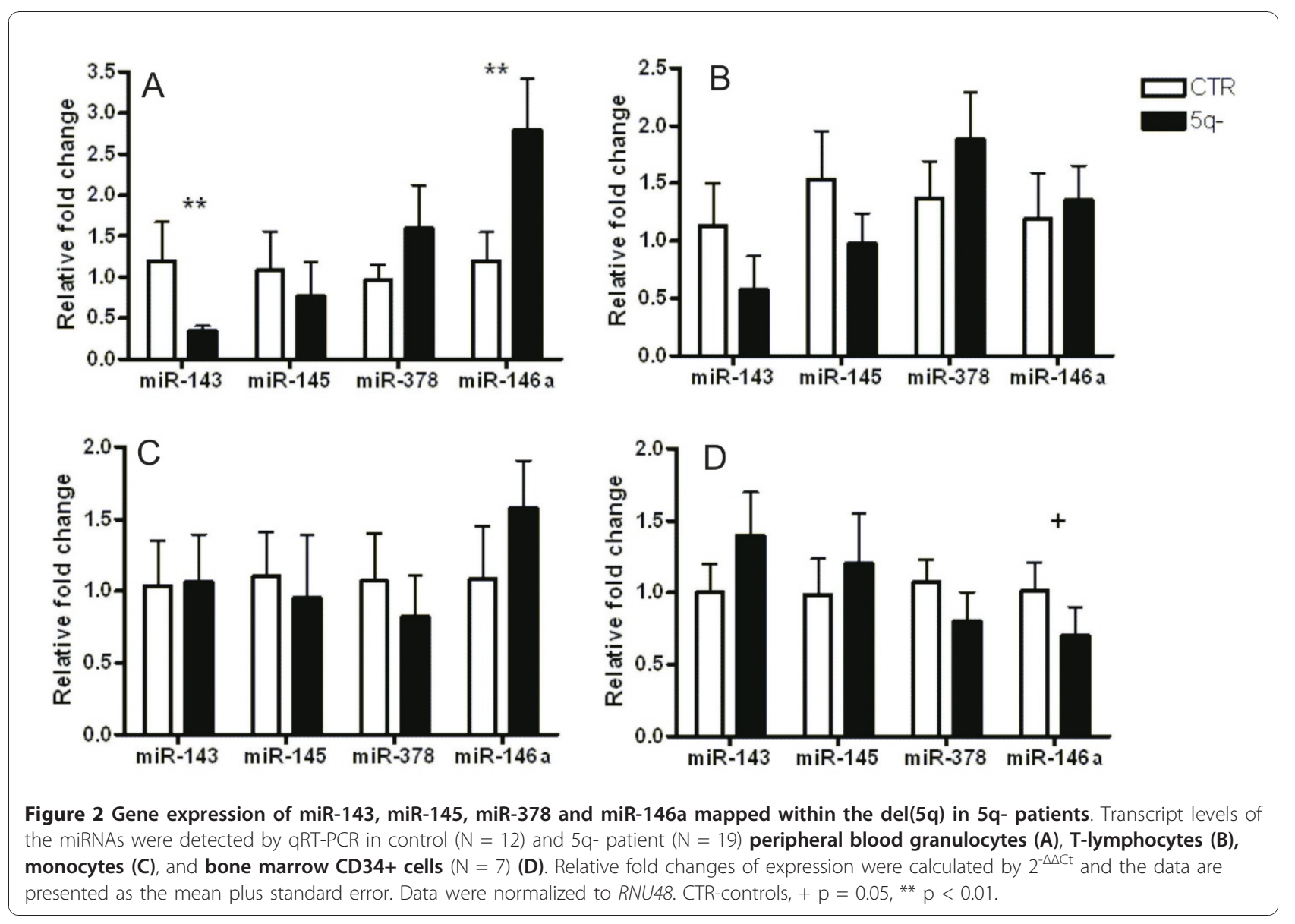

As shown in the target list, we noted several potential target genes (e.g. KLF4, LEF1, SPI1) with an important function in the regulation of hematopoiesis. KLF4 gene is a member of the Kruppel-like family of factors (KLFs) that play essential roles in erythrocyte and lymphocyte development. KLF4 is expressed in a stage-specific pattern during myelopoiesis and its forced expression in hematopoietic stem cells promotes monocyte differentiation [21]. KLF4 is targeted by transcriptional factor PU.1 (SPI1) that cooperates with CEBPA to control myeloid cell development. LEF1 is a lymphoid enhancer-binding factor which mediates proliferation, survival and differentiation of granulocyte progenitors. Reduction/ deficiency of $L E F 1$ gene leads to the defective maturation of myeloid progenitors in patients with severe congenital neutropenia [22]. The down-regulation of these targets in 5q- patients may be associated with impaired cell differentiation. Taken together, our data underline complexity of the miRNA/target regulatory network that is being analyzed in detail by functional studies.

Our study demonstrates that the specific miRNA signature (mostly miRNA overexpressions) is associated with 5 q- phenotype. Especially, miR-34a was highly upregulated in $5 \mathrm{q}$ - syndrome patients. Notably, we found

Table 1 Potential target genes of deregulated miRNAs in $\mathbf{5 q - p a t i e n t s}$

\begin{tabular}{|c|c|c|c|}
\hline miRNA ID & Location & Expression in 5q- & Target genes with inverse expression \\
\hline hsa-miR-34a & $1 \mathrm{p} 36.22$ & over & LEF1, KLF4, SPI1, NR4A2 \\
\hline hsa-miR-223 & $\mathrm{Xq} 12$ & over & EBF3, PDE4B, PLEKHM1, RHOB \\
\hline hsa-miR-199a & $19 p 13.2$ & over & CCDC34, MRPL22 \\
\hline hsa-miR-335 & $7 q 32.2$ & over & ETF1 \\
\hline hsa-miR-128b & $3 p 22.3$ & down & GPAM, RGL2 \\
\hline hsa-miR-520c & $19 q 13.42$ & down & CYBRD1 \\
\hline
\end{tabular}

Messenger RNA profiles of CD34+ cells in the tested subjects were assayed by microarrays and putative targets of deregulated miRNAs ( $p \leq 0.05$ ) were determined by prediction algorithm tools. The integrative analysis of differently expressed mRNAs and predicted targets identified genes with an inverse expression pattern. 
the up-regulation of several miRNAs (miR-10a/b, miR126, miR-99b, and miR-130a) implicated in the regulation of HOX genes. Against our expectation, not all miRNAs at del(5q) displayed reduced gene expression. The analysis of mRNA expressions and predicted targets showed that aberrantly expressed miRNAs might be involved in the pathogenesis of 5q- syndrome by the modulation of their target genes.

\section{Methods}

\section{Samples}

Bone marrow (BM) CD34+ cells were obtained from 7 patients and 5 controls. Control CD34+ cells were purchased from Lonza (Basel, Switzerland). Peripheral blood (PB) granulocytes, T-lymphocytes and monocytes were obtained from 19 patients and 12 controls. All patients fulfilled WHO diagnostic criteria of 5q- syndrome. All subjects provided the informed consent and the study was approved by the Local Ethics Committee.

Mononuclear cells and granulocytes were separated by Ficoll-Hipaque density gradient centrifugation (GE Health Care, Little Chalfont, UK). Other cell fractions were isolated by magnetic column separation using MACS kits (Myltenyi Biotech, Bergisch Gladbach, Germany): Direct CD34+ Progenitor Cell Isolation Kit, CD3 T-Cells Isolation Kit, and CD14 Monocytes Isolation Kit. The purity of cell populations was controlled using FACSAria (Becton Dickinson, San Jose, CA) and always exceeded 95\%.

\section{Analysis of miRNA expression}

Total RNA (800 ng) was reverse transcribed into cDNA by TaqMan MicroRNA Reverse Transcription Kit (Applied Biosystems, Foster City, CA). TaqMan Human MicroRNA Arrays v1.0 (Applied Biosystems) with 365 probes were analyzed on 7900HT Fast Real-Time PCR System (Applied Biosystems). The array data were processed using SDS v2.3 (Applied Biosystems) and Genesis 1.6.0Beta1 software http://genome.tugraz.at/. Unsupervised hierarchical clustering of the data was done by average linkage and Euclidean distance. Singleplex qRTPCR of $m i R-143, m i R-145, m i R-378$ and $m i R-146 a$ was performed on RotorGene 3000 instrument (Qiagen, Hilden, Germany) using TaqMan MicroRNA Expression Assays (Applied Biosystems). The PCR reactions were performed in duplicates. Relative gene expressions of these four miRNAs correlated $(\mathrm{r}=0.97, \mathrm{p}<0.01)$ to those detected by multiplex qRT-PCR Array in bone marrow samples.

All miRNA data were normalized to the endogenous control RNU48 and relative fold changes of gene expression were calculated by $\Delta \Delta \mathrm{C}_{\mathrm{T}}$ method. The statistical significance between miRNA expression of patients and controls was calculated by Student's t-test. The p-values were adjusted by Bonferroni correction for multiple testing.

Putative target genes were predicted using algorithm tools TargetScan $5.1 \mathrm{http}$ //www.targetscan.org and PicTar http://pictar.mdc-berlin.de.

\section{Additional material}

Additional file 1: Fold changes of miRNA expressions in 5qpatients detected by TaqMan MicroRNA Arrays. The data are presented as ratio of averaged expression in $5 \mathrm{q}$ - patients to averaged expression in controls for particular miRNAs. Only fold changes with $p<$ 0.05 after Bonferroni correction are shown.

\section{Acknowledgements}

We wish to thank Prof. Ing. Kyra Michalova, DrSc. (Center of Oncocytogenetics, Faculty Hospital and First Faculty of Medicine, Charles University in Prague) for cytogenetic data. We thank Mgr. Iva Sakmaryova (Institute of Rheumatology, Prague) who kindly provided us 7900HT Fast Real-Time PCR System. This study was supported by GA CR 301/09/P579 and research task No.00023736 from the Ministry of Health of the Czech Republic.

\section{Author details}

'Department of Molecular Genetics, Institute of Hematology and Blood Transfusion, Praque, Czech Republic. ${ }^{2} 1$ st Medical Department of Charles University Hospital, Prague, Czech Republic. ${ }^{3}$ Institute of Clinical and Experimental Hematology, 1st Faculty of Medicine, Charles University, Prague, Czech Republic.

\section{Authors' contributions}

$H V, M G, M B$ and AV performed the experimental work and organized data. MDM analyzed array data. HV interpreted data and drafted the manuscript. $\mathrm{RN}$ and JC critically reviewed the manuscript and provided concepts. All authors read and approved the final manuscript.

\section{Competing interests}

The authors declare that they have no competing interests.

Received: 13 November 2010 Accepted: 6 January 2011 Published: 6 January 2011

\section{References}

1. Bruchova $H$, Merkerova M, Prchal JT: Aberrant expression of microRNA in polycythemia vera. Haematologica 2008, 93:1009-1016.

2. Guglielmelli P, Tozzi L, Pancrazzi A, Bogani C, Antonioli E, Ponziani V, Poli G, Zini R, Ferrari S, Manfredini R, Bosi A, Vannucchi AM, MPD Research Consortium: MicroRNA expression profile in granulocytes from primary myelofibrosis patients. Exp Hematol 2007, 35:1708-1718.

3. Pons A, Nomdedeu B, Navarro A, Gaya A, Gel B, Diaz T, Valera S, Rozman M, Belkaid M, Montserrat E, Monzo M: Hematopoiesis-related microRNA expression in myelodysplastic syndromes. Leuk Lymphoma 2009, 14:1-6.

4. Hussein K, Theophile K, Büsche G, Schlegelberger B, Göhring G, Kreipe H, Bock O: Aberrant microRNA expression pattern in myelodysplastic bone marrow cells. Leuk Res 2010, 34:1169-1174.

5. Vasikova A, Belickova M, Budinska E, Cermak J: A distinct expression of various gene subsets in CD34+ cells from patients with early and advanced myelodysplastic syndrome. Leuk Res 2010, 34:1566-1572.

6. Shen WF, Hu YL, Uttarwar L, Passegue E, Largman C: MicroRNA-126 regulates HOXA9 by binding to the homeobox. Mol Cell Biol 2008, 28:4609-4619.

7. Poppe B, Vandesompele J, Schoch C, Lindvall C, Mrozek K, Bloomfield CD, Beverloo HB, Michaux L, Dastugue N, Herens C, Yigit N, De Paepe A, Hagemeijer A, Speleman F: Expression analyses identify MLL as a prominent target of $11 \mathrm{q} 23$ amplification and support an etiologic role 
for MLL gain of function in myeloid malignancies. Blood 2004, 103:229-235.

8. Thorsteinsdottir U, Mamo A, Kroon E, Jerome L, Bijl J, Lawrence HJ, Humphries K, Sauvageau G: Overexpression of the myeloid leukemiaassociated Hoxa9 gene in bone marrow cells induces stem cell expansion. Blood 2002, 99:121-129.

9. Chang TC, Wentzel EA, Kent OA, Ramachandran K, Mullendore M, Lee KH, Feldmann G, Yamakuchi M, Ferlito M, Lowenstein CJ, Arking DE, Beer MA, Maitra A, Mendell JT: Transactivation of miR-34a by p53 broadly influences gene expression and promotes apoptosis. Mol Cell 2007, 26:745-752.

10. Bruchova H, Yoon D, Agarwal AM, Mendell J, Prchal JT: Regulated expression of miRNAs in normal and polycythemia vera erythropoiesis. Exp Hematol 2007, 35:1657-1667.

11. Pase L, Layton JE, Kloosterman WP, Carradice D, Waterhouse PM, Lieschke GJ: miR-451 regulates zebrafish erythroid maturation in vivo via its target gata2. Blood 2009, 113:1794-1804.

12. Pulikkan JA, Dengler V, Peramangalam PS, Peer Zada AA, Müller-Tidow C, Bohlander SK, Tenen DG, Behre G: Cell-cycle regulator E2F1 and microRNA-223 comprise an autoregulatory negative feedback loop in acute myeloid leukemia. Blood 2010, 115:1768-1778.

13. Felli N, Pedini F, Romania P, Biffoni M, Morsilli O, Castelli G, Santoro S, Chicarella S, Sorrentino A, Peschle C, Marziali G: MicroRNA 223-dependent expression of LMO2 regulates normal erythropoiesis. Haematologica 2009, 94:479-486.

14. Bousquet M, Quelen C, Rosati R, Mansat-De Mas V, La Starza R, Bastard C, Lippert E, Talmant P, Lafage-Pochitaloff M, Leroux D, Gervais C, Viguié F, Lai JL, Terre C, Beverlo B, Sambani C, Hagemeijer A, Marynen P, Delsol G, Dastugue N, Mecucci C, Brousset P: Myeloid cell differentiation arrest by miR-125b-1 in myelodysplastic syndrome and acute myeloid leukemia with the $t(2 ; 11)(p 21 ; q 23)$ translocation. J Exp Med 2008, 205:2499-506.

15. Guo S, Lu J, Schlanger R, Zhang H, Wang JY, Fox MC, Purton LE, Fleming HH, Cobb B, Merkenschlager M, Golub TR, Scadden DT: MicroRNA miR-125a controls hematopoietic stem cell number. Proc Natl Acad Sci USA 2010, 107:14229-14234.

16. Mi S, Lu J, Sun M, Li Z, Zhang H, Neilly MB, Wang Y, Qian Z, Jin J, Zhang Y, Bohlander SK, Le Beau MM, Larson RA, Golub TR, Rowley JD, Chen J: MicroRNA expression signatures accurately discriminate acute lymphoblastic leukemia from acute myeloid leukemia. Proc Natl Acad Sci USA 2007, 104:19971-19976.

17. Kotani A, Ha D, Hsieh J, Rao PK, Schotte D, den Boer ML, Armstrong SA, Lodish HF: miR-128b is a potent glucocorticoid sensitizer in MLL-AF4 acute lymphocytic leukemia cells and exerts cooperative effects with miR-221. Blood 2009, 114:4169-4178.

18. De Marchis ML, Ballarino M, Salvatori B, Puzzolo MC, Bozzoni I, Fatica A: A new molecular network comprising PU.1, interferon regulatory factor proteins and miR-342 stimulates ATRA-mediated granulocytic differentiation of acute promyelocytic leukemia cells. Leukemia 2009, 23:856-862.

19. Boultwood J, Pellagatti A, Cattan H, Lawrie CH, Giagounidis A, Malcovati L, Della Porta MG, Jädersten M, Killick S, Fidler C, Cazzola M, HellströmLindberg E, Wainscoat JS: Gene expression profiling of CD34+ cells in patients with the 5q- syndrome. Br J Haematol 2007, 139:578-589.

20. Starczynowski DT, Kuchenbauer F, Argiropoulos B, Sung S, Morin R, Muranyi A, Hirst M, Hogge D, Marra M, Wells RA, Buckstein R, Lam W, Humphries RK, Karsan A: Identification of miR-145 and miR-146a as mediators of the 5q- syndrome phenotype. Nat Med 2010, 16:49-58.

21. Feinberg MW, Wara AK, Cao Z, Lebedeva MA, Rosenbauer F, Iwasaki $H$, Hirai H, Katz JP, Haspel RL, Gray S, Akashi K, Segre J, Kaestner KH, Tenen DG, Jain MK: The Kruppel-like factor KLF4 is a critical regulator of monocyte differentiation. EMBO J 2007, 26:4138-4148.

22. Skokowa J, Cario G, Uenalan M, Schambach A, Germeshausen M, Battmer K, Zeidler C, Lehmann U, Eder M, Baum C, Grosschedl R, Stanulla M, Scherr M, Welte K: LEF-1 is crucial for neutrophil granulocytopoiesis and its expression is severely reduced in congenital neutropenia. Nat Med 2006, 12:1191-1197.

doi:10.1186/1756-8722-4-1

Cite this article as: Votavova et al:: Differential Expression of MicroRNAs in CD34+ Cells of 5q- Syndrome. Journal of Hematology \& Oncology 2011 4:1.

\section{Submit your next manuscript to BioMed Central and take full advantage of:}

- Convenient online submission

- Thorough peer review

- No space constraints or color figure charges

- Immediate publication on acceptance

- Inclusion in PubMed, CAS, Scopus and Google Scholar

- Research which is freely available for redistribution

Submit your manuscript at www.biomedcentral.com/submit
C Biomed Central 